$8^{\text {th }}$ International Workshop on Simulation for Energy, Sustainable Development \& Environment

$17^{\text {th }}$ International Multidisciplinary Modeling \& Simulation Multiconference

ISSN 2724-0061 ISBN 978-88-85741-52-2 (C) 2020 The Authors.

DOI: $10.46354 /$ i3m.2020.sesde.003

\title{
A Model for Adjusting Dietary Estimates of Greenhouse Gases Towards OECD Food Estimates
}

\author{
Susan J Lincke* and Joy Wolf \\ ${ }^{1}$ University of Wisconsin-Parkside, 900 Wood Rd, Kenosha, WI, 53141, USA \\ *Corresponding author. Email address: lincke@uwp.edu
}

\begin{abstract}
Research has shown that the meat-based portion of diets has a most serious effect related to greenhouse gases. Many studies rely on portion estimations, assuming a 'high-level' of daily meat consumption of $100 \mathrm{~g}$ and an average consumption of 2000 kcal. This meat estimate is less than one McDonalds quarter pounder. The Organization for Economic Co-Operation and Development (OECD) provides annual estimates of national meat consumption, where six nations average rank above the $200 \mathrm{~g}$ mark. We focus on EU and US, since there are both OECD data and dietary studies available for these higher-meat consumption nations. The OECD meat consumption for EU is at $189 \mathrm{~g}$ and US at $270 \mathrm{~g}$ daily. We prorate studies' research to assume the meat portion is equal to the OECD statistics and also prorate to a higher dietary consumption level of $2400 \mathrm{kcal}$. We accomplish this by providing a mathematical model and example results for 8 studies. These are analyzed for reasonableness by observing the greenhouse gases per kcal for meat and non-meat portions of diet. Our results provide an upper bound of the effects of meat consumption, not including fish, as well as to contrast existing studies using similar metrics. We found that both kcal estimates and meat consumption are strong drivers of GHG levels, and research should not be complacent with lower food estimates.
\end{abstract}

Keywords: greenhouse gas emissions; food consumption; vegetarian diet; sustainable diet; modeling \& simulation.

\section{Introduction}

As climate change is becoming a greater concern, it becomes important to evaluate the major causes of greenhouse gases (GHG), in order to evaluate ways to reduce them. It is well-known that electricity, fuel for transportation and heating, and agriculture are major sources of climate change. Specifically, within agriculture the production of meat has been shown to be problematic to shifting atmospheric gasses such as methane and carbon dioxide. In this study, the research focuses on creating a model to evaluate changes in diets, by leveraging previous research, and determining how changes may affect greenhouse gas impact.

A number of studies have evaluated the $\mathrm{CO}_{2}-$ equvialent (CO2e) GHG of various types of diets (high or low meat-eater, vegetarian and vegan) by estimating national consumption patterns (e.g., Baroni et al. 2007; González-García et al. 2018; Gerber et al. 2013). We noticed that many studies that provide estimates for dietary choices showed low meat consumption statistics: often a 'high' meat eater ate at or near $100 \mathrm{~g}$ of meat daily (e.g., Biesbroek et al. 2013; Gonzalez-Garcia et al. 2018; Scarborough et al. 2014). For portion estimation, consider that one McDonalds' quarter-pounder has $113 \mathrm{~g}$ of meat and is eaten in one meal. However, meat eaters tend to eat meat for 2-3 meals per day. Since a quarter pounder is a moderate amount of meat, $100 \mathrm{~g}$ seems a low statistic for daily intake for a 'high' meat eater in a western nation. (McDonald's quarter-pounder is an excellent comparator, since it is sold worldwide.) This detail is important since meat consumption significantly impacts GHG estimates for diet.

(C) 2020 The Authors. This article is an open access article distributed under the terms and conditions of the Creative Commons Attribution (CC BY-NC-ND) license (https://creativecommons.org/licenses/by-nc-nd/4.0/). 
Research has traditionally relied on reported portion sizes to estimate diet (e.g., Biesbroek et al. 2013; Soret et al. 2014; Sjörs et al. 2016; Scarborough et al. 2014), although sources indicate that people report eating less than they actually do by $20 \%$ or more (Berners-Lee et al. 2012). Greger (2019) writes that people on diets tend to report what they intended or wished to eat, and not what they actually ate. Our study uses as an alternative, national aggregate statistics as reported to the Organization for Economic Co-operation and Development (OECD).
Secondly, if portion sizes of meat is low, total food consumption is also likely low. Also, portion sizes vary due to changes in consumption over time. Table 1 shows many studies in wealthy countries have considered the recommended diet of $2000 \mathrm{kcal}$ a day, while others study a more realistic diet of 2400-2700 kcal per day. The GHG estimates of a diet with too low an estimate of meat consumption and/or total consumption does not offer a realistic picture of the contribution of diet to GHG. A goal of our study is to proportion the results from studies of a recommended $2000 \mathrm{kcal} /$ day to a more realistic and standard $2400 \mathrm{kcal} /$ day.

Table 1. GHG study results for dietary consumption patterns

\begin{tabular}{|c|c|c|c|c|c|c|c|}
\hline \multirow{2}{*}{ Nation } & \multirow{2}{*}{$\begin{array}{l}\text { g/day } \\
\text { meat }\end{array}$} & \multirow{2}{*}{ kcal/day } & \multirow{2}{*}{$\begin{array}{l}\text { GHG } \\
\mathrm{kg} / \mathrm{yr}\end{array}$} & \multicolumn{3}{|c|}{ GHG kg/day } & \multirow{2}{*}{ Source } \\
\hline & & & & Standard & Vegetarian & Vegan & \\
\hline Denmark & 205 & 2726 & 2029 & 3.42 & & & (Saxe et al. 2013; Gonzalez-Garcia, 2018: S31) \\
\hline Germany & 103 & 2000 & 2051 & 5.62 & 4.27 & 2.63 & $\begin{array}{l}\text { (Meier and Christen, 2013; Gonzalez-Garcia 2018: } \\
\text { S39, S42-43) }\end{array}$ \\
\hline Netherlands & 130 & 2537 & 2117 & 5.8 & 3.2 & 2.65 & $\begin{array}{l}\text { (Van de Kamp et al., 2018; Gonzalez-Garcia 2018: } \\
\text { S44, S48, S50; van Dooren et al. 2014) }\end{array}$ \\
\hline Sweden & 110 & 2412 & 1898 & 5.2 & & & (Röös et al. 2014) \\
\hline UK & 110 & 2000 & 2624 & 7.19 & 3.81 & 2.89 & $\begin{array}{l}\text { (Scarborough et al. 2014; Gonzalez-Garcia 2018: } \\
\text { S12-S14) }\end{array}$ \\
\hline UK & 88 & 3548 & 2701 & 7.4 & & & (Berners-Lee et al., 2012) \\
\hline $\begin{array}{l}\text { USA: 7th Day } \\
\text { Adv. }\end{array}$ & 64 & 2000 & 1113 & 3.05 & 2.16 & & (Soret et al. 2014) \\
\hline USA & 365 & 2000 & 4902 & 13.43 & & & $\begin{array}{l}\text { (Saez-Almendros et al. 2013; Gonzalez-Garcia } 2018 \\
\text { S56) }\end{array}$ \\
\hline
\end{tabular}

Thirdly, food wastage is rarely accounted for, particularly when a recommended (2000 kcal) diet is considered. Gonzalez-Garcia et al.'s (2018) comprehensive study found that dietary calculations were not carried out consistently, and generally considered cultivation to farm-gate or to retail, but not to consumer. The UK Berners-Lee et al. (2012) study considers extraneous factors affecting GHG beyond estimated consumption with their estimate of 3548 daily kcal. Eshel and Martin (2005) calculate estimated food production at $3774 \mathrm{kcal} /$ person/day in the U.S. Therefore, our upper estimate of $2400 \mathrm{kcal} /$ day should be a very low estimate.

Fourthly, there may be sample error, when certain age groups or lifestyles are over or underrepresented, or different calculations result in grossly varying numbers. For example, in studying annual per capita GHG for a U.S. standard diet, one may contrast the Adventist Health Study 2 at $1113 \mathrm{Kg} \mathrm{CO2e/year,} \mathrm{Shrink}$ That Footprint website at $2500 \mathrm{Kg} \mathrm{CO} 2 \mathrm{e} /$ year, and Saez-Almendros et al. (2013) at $4902 \mathrm{Kg}$ CO2e/year. These differ by over 4 times! One goal of our research is to enable adjusting for assumptions, analyze and attempt to explain differences, and provide a mechanism where projections can be made as diet changes.

The OECD, with its 36 member nations, provides upto-date estimates of meat consumption for member nations within a database (OECD, 2019). This database indicates that only 10 of 34 countries have average daily 'retail' meat consumption lower than $100 \mathrm{~g}$ while 6 countries report meat consumption over 200 g per day. Many research studies (see Table 1) estimated meat consumption lower than that reported by the OECD for retail consumption. This means that our measure of 'high' meat consumption should be adjusted. We use a combination of OECD and research data to provide higher (and arguably more realistic) estimates for national dietary GHG data.

The OECD database provides statistics per nation, either as tons of 'carcass weight', or as 'retail weight per capita'. We work with the per capita estimates of retail weight, which is calculated as $70-88 \%$ of carcass weight. OECD statistics may average higher, because stores do not sell all of their meat and consumers may discard or chop off parts of purchased meat. However, for GHG purposes, it does not matter if the meat was consumed or discarded. The UK Berners-Lee et al. (2012) study considers extraneous factors affecting GHG beyond estimated consumption, but offers an adjustment only to their study. OECD statistics provides a high-end nationally-provided statistic (as opposed to individual dietary estimates) as a dietary basis for GHG effects. This counters study results, which appear low.

Table 1 illustrates data from the studies that we will be working with, showing annual $\mathrm{CO} 2 \mathrm{e}$ (GHG) estimated in $\mathrm{kg} / \mathrm{day}$ and $\mathrm{kg} / \mathrm{year}$, and the corresponding meat consumption. These studies have estimated local diets and we project their results with OECD member nation statistics and contrast them with 
each other. Our analytic model enables testing of different food amounts, in order to estimate the impact of changes in diet on greenhouse gasses. In this study we enlarge the meat portion of the diet to OECD statistics and correspondingly reduce the nonmeat portion of the diet. We assume the original paper's distribution of meat accords with OECD statistics (although this is not necessarily true). We calculate results for 2000 and 2400 kcal diets. We are not aware of other modeling studies that project from existing studies. (Computer studies tend to work with user interfaces to collect and display GHG emissions, e.g., Ganglbauer et al. 2012, 2013.)

In section two we detail our analytic model. In section three we provide results and analysis, and finally conclude in section four.

\section{Method}

OECD (2019) provides statistics by nation for the 'retail consumption' each of beef, pig, poultry, sheep, in Kg. We calculate the greenhouse gases (GHG) or CO2e for each amount of meat from UN FAO data from the source: "Tackling Climate Change through Livestock" (Gerber et al. 2013). It provides multiple numbers per each of beef, pig, poultry and sheep, considering grazing, mixed and/or intensive types of farming. Grazing farming generally produces more GHG (Gerber et al. 2013). We selected the total (or averaged) emission intensity considering all forms of farming. This favors mixed/intensive farming, which is more commonly used. Using these UN and OECD sources, we calculate the average meat consumption and resulting GHG per person on a national basis, where 'beef' equals the $\mathrm{kg}$ of beef for nation $\mathrm{x}$, etc. Equation (1) provides the annual average production per person of GHG for just the meat consumption (of beef, pig, poultry and sheep) for a particular nation:

$$
\begin{gathered}
\text { GhgMeat }=46.2 * \text { beef }+6.1 * \text { pig }+5.4 * \text { poultry } \\
+23.8 * \text { sheep }
\end{gathered}
$$

We took average kcal per meat type from www.nutritionix.com. Commonly statistics are provided as kcal per 100 grams consumed. The kcal of this consumption (in grams/day) are calculated using average kcal statistics for each meat, as follows:

$$
\text { KcalMeat }=\frac{[(291 * \text { beef }+220 * \text { pig }+238 * \text { poultry }+294 * \text { sheep }) * 10]}{365}
$$

where kcal/100 grams are multiplied by 10 to obtain $\mathrm{kcal}$ per $\mathrm{kg}$ that the meat is measured in. These three statistics are generated solely from OECD and UN data, independent of the previous research. The next calculations are derived from various research studies in relation to this OECD-UN data.

The first question is what is the difference in meat consumption in published studies versus OECD-UN statistics? We calculate a ratio of the published research study's estimated meat consumed divided by the OECD-provided data, adjusting for reporting in grams or $\mathrm{Kg}$ :

Ratio $=\frac{\text { MeatCons }(\text { sudy })}{\text { MeatCons }(\text { OECD })}$

This ratio demonstrates a delta in studies' GHG results. However, we recognize that we introduce an error in that MeatConsumed(OECD) does not include fish.

We next consider the effects on GHG according to the OECD-UN data. To accomplish this, we need to separate out the kcal and GHG estimates for the meat versus non-meat portion of a study's diet. We subtract out the study's estimated GHG for meat consumption and replace it with the OECD-UN's estimated GHG for meat consumed. However, we need to prorate kcal, since we want to assume no change in $\mathrm{kcal} /$ day. (After all, the study authors assumed a particular $\mathrm{CO}_{2} \mathrm{e}$ based on the kcal.) The data we collected from research studies include (1) the meat consumption per day, (2) daily kcal, and (3) the CO2e per day or year, per person. We estimate the CO2e attributed to meat as the OECDUN GHG statistics times the ratio of study-to-OECDUN meat consumption:

GhgMeat $($ study $)=$ GhgMeat $($ OECD $) *$ Ratio

The Kcal attributed to meat are proportioned similarly. An error may result, since we are assuming that the proportions of the various meats is the same in the research versus OECD reporting. We can now proportion the amount of kcal and GHG to non-meat portions of the diet:

KcalNonMeat $($ study $)=K \operatorname{cal}($ study $)-K \operatorname{calMeat}($ study $)(5)$

The next step is to proportion the full OECD-UN estimate for meat in the diet. Here we calculate the additional (extra) meat estimated by the OECD data:

$X M e a t=$ MeatCons $(O E C D)-$ MeatCons $(s t u d y)$

Then we calculate the kcal and GHG for the additional (extra) meat using OECD-UN totals, where these totals are in the equivalent measuring units (e.g, $\mathrm{g} /$ day or $\mathrm{Kg} /$ year):

$$
\begin{aligned}
& \text { KcalXMeat }=\text { XMeat } * \frac{\text { KcalMeat }(O E C D)}{\text { MeatCons }(O E C D)} \\
& \text { GhgXMeat }=\text { XMeat } * \frac{\text { GhgMeat }(O E C D)}{\text { MeatCons }(\text { OECD })}
\end{aligned}
$$

We must then subtract out the reduced proportion of non-meat (NM) diet for an equivalent amount of kcal:

$$
\begin{aligned}
& \text { KcalLessNM }=\text { KcalNonMeat }(\text { study })-\text { KcalXMeat } \\
& \text { GhgLessNM }=\text { GhgNonMeat }(\text { study }) * \frac{\text { KcalLessNM }}{\text { KcalNonMeat }(\text { study })}
\end{aligned}
$$

Finally, we can determine the end result of the increased rate of meat consumption, providing new CO2e statistics by summing the meat and non-meat parts of the diet. 
An important statistic is the CO2e estimate per kcal for meat and non-meat, which helps to determine the efficiency of a portion of a diet (e.g.):

$\frac{G h g(\text { Non }) \text { Meat }}{\text { kcal }}=\frac{\text { Ghg(Non)Meat }(\text { study })}{\text { Kcal(Non)Meat }(\text { study })}$

\section{Results and Analysis}

We reviewed calculations from 8 studies for nations known for high meat consumption for which OECD data and dietary studies exist: U.S.A. and European Union. OECD statistics are not available for EU member states. In a special case of Sweden and Denmark, OECD statistics were available for neighboring, culturallysimilar Norway. So those two studies are projected using both sets of OECD statistics.

Figure 1 shows $\mathrm{CO} 2 \mathrm{e}$ data in graph form as original paper data (blue bar) and revised with OECD-changed meat consumption for a fixed 2000 (red bar) and 2400 kcal diet (gray bar). The names of the nations include the original kcal associated with the blue bar results. Denmark (DK) and Sweden are shown using both OECD EU and Norway (NW) data.

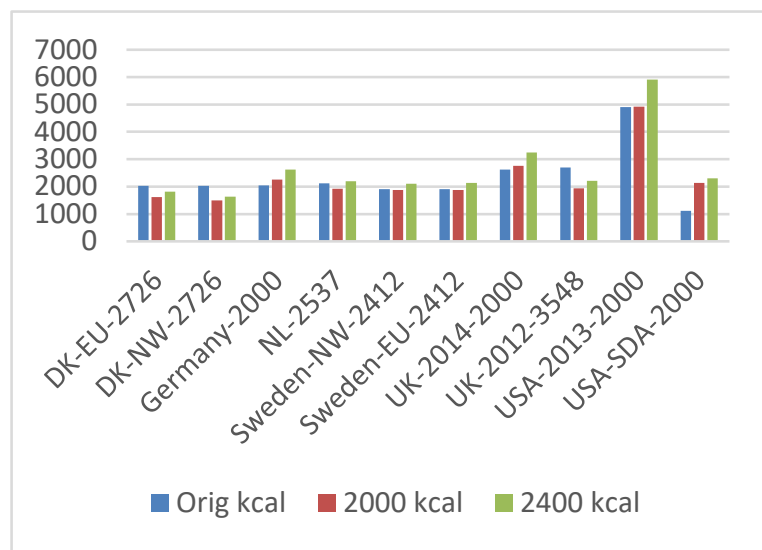

Figure 1: GHG Emissions for Original vs. 2000 vs. 2400 kcal.

Table 2. A comparison of 8 studies from US and EU

\begin{tabular}{|c|c|c|c|c|c|c|c|c|c|c|c|}
\hline \multirow[b]{2}{*}{ Study } & \multicolumn{3}{|c|}{ Paper statistics } & \multicolumn{2}{|c|}{ Derived OECD } & \multicolumn{3}{|c|}{ Revised Calories 2000} & \multicolumn{3}{|c|}{ Revised calories $>=2400$} \\
\hline & $\begin{array}{l}\text { g/day } \\
\text { meat }\end{array}$ & kcal/day & $\begin{array}{l}\text { Ghg } \\
\mathrm{kg} / \mathrm{yr}\end{array}$ & $\begin{array}{l}\text { g/day } \\
\text { meat }\end{array}$ & $\begin{array}{l}\text { Ghg } \\
\mathrm{kg} / \mathrm{yr}\end{array}$ & kcal/day & $\begin{array}{l}\text { Ghg } \\
\text { g/day }\end{array}$ & $\begin{array}{l}\text { Ghg } \\
\mathrm{kg} / \mathrm{yr}\end{array}$ & kcal/day & $\begin{array}{l}\text { Ghg } \\
\text { g/day }\end{array}$ & $\begin{array}{c}\text { Ghg } \\
\mathrm{kg} / \mathrm{yr}\end{array}$ \\
\hline $\begin{array}{l}\text { DK (Saxe et al. 2013) } \\
\text { (EU) }\end{array}$ & 205 & 2726 & 2029 & 189 & 873 & 2000 & 4.45 & 1623 & 2726 & 5.41 & 1975 \\
\hline $\begin{array}{l}\text { DK (Saxe et al. 2013) } \\
\text { (NW) }\end{array}$ & 205 & 2726 & 2029 & 153 & 948 & 2000 & 4.12 & 1503 & 2726 & 4.80 & 1751 \\
\hline $\begin{array}{l}\text { Germany (Meier \& } \\
\text { Christen 2013) (EU) }\end{array}$ & 103 & 2000 & 2051 & 189 & 873 & 2000 & 6.20 & 2263 & 2400 & 7.19 & 2623 \\
\hline $\begin{array}{l}\text { NL (van de Kamp et al. } \\
\text { 2018) (EU) }\end{array}$ & 130 & 2537 & 2117 & 189 & 873 & 2000 & 5.28 & 1927 & 2537 & 6.28 & 2293 \\
\hline $\begin{array}{l}\text { Sweden (Röös et al. } \\
\text { 2014) (NW) }\end{array}$ & 110 & 2412 & 1902 & 153 & 948 & 2000 & 5.13 & 1872 & 2412 & 5.77 & 2107 \\
\hline $\begin{array}{l}\text { Sweden (Röös et al. } \\
\text { 2014) (EU) }\end{array}$ & 110 & 2412 & 1902 & 189 & 873 & 2000 & 5.14 & 1876 & 2412 & 5.87 & 2144 \\
\hline $\begin{array}{l}\text { UK (Scarborough et al. } \\
\text { 2014) (EU) }\end{array}$ & 110 & 2000 & 2624 & 189 & 873 & 2000 & 7.56 & 2758 & 2400 & 8.89 & 3246 \\
\hline $\begin{array}{l}\text { UK (Berners-Lee et al., } \\
\text { 2012) (EU) }\end{array}$ & 88 & 3548 & 2701 & 189 & 873 & 2000 & 5.31 & 1937 & 3548 & 8.22 & 3001 \\
\hline $\begin{array}{l}\text { USA (Saez-Almendros } \\
\text { et al. 2013) (USA) }\end{array}$ & 365 & 2000 & 4902 & 270 & 1613 & 2000 & 13.48 & 4919 & 2400 & 16.20 & 5912 \\
\hline $\begin{array}{l}\text { USA SDA (Soret et al. } \\
\text { 2014) }\end{array}$ & 64 & 2000 & 1113 & 270 & 1613 & 2000 & 5.86 & 2141 & 2400 & 6.30 & 2299 \\
\hline
\end{tabular}

Table 2 illustrates the results for the eight studies, contrasting the original study with the OECD-changed meat consumption adjusting to the paper's kcal value. In the first columns of Table 2 we show the paper's original statistics. The second set of columns revise the meat portion using OECD-UN statistics. The third and fourth sets of columns show the revised numbers using OECD-changed meat consumption, assuming either the $2000 \mathrm{kcal} /$ day and $2400 \mathrm{kcal} /$ day, unless the original paper was calculated above $2400 \mathrm{kcal}$, in which case we kept their original kcal/day statistic. The portion of meat eaten in both Revised Calories columns are consistent with the OECD meat-consumption data.

\subsection{Effectiveness of Numbers}

One can argue that the OECD-UN meat consumption numbers provide national aggregated statistics and thus a more realistic perspective for calculating the GHG of diets than dietary estimates. If the OECD-UN meat consumption numbers are more accurate, then the determination is which kcal/day should be used: the recommended $2000 \mathrm{kcal} /$ day; possibly a more reasonable estimate of $2400 \mathrm{kcal} /$ day (or more); or a value that considers food discard at the store and home. We argue that the higher values offer a more realistic picture of generated GHG.

The E.U. is a series of nations and cultures with different eating styles, and a couple of OECD statistics may be insufficient to estimate them accurately. However, countries with reputations for low meat, such as Italy's Mediterranean diet, has tripled its meat 
consumption in the last 50 years and now Italy ranks at the 'high' meat consumption of $113 \mathrm{~g} /$ day (Farchi et al., 2017), which is commensurate with other EU dietary survey studies. Secondly, OECD numbers are estimates and while previous research arguably provided low numbers, these numbers may provide (hopefully) a reasonable upper bound average. Thirdly, we introduce next a mathematical approach to investigate the reasonableness of the results.

One way to determine reasonableness is to look at the CO2e/kcal. We calculated the $\mathrm{CO} 2 \mathrm{e} / \mathrm{kcal}$ for meat and non-meat portions of the diet. The meat $\mathrm{CO} 2 \mathrm{e} / \mathrm{kcal}$ is calculated from OECD data for the nation, then the remainder of the CO2e for kcal is calculated based on the non-meat portion. One possible problem is if the non-meat number is abnormally high or low, compared to other studies. An example is the U.S. (Saez-Almendros et al. 2013) study which has a high non-meat portion of the diet. Another problem may be if the non-meat portion of a meat-eater diets is more efficient than a vegetarian or vegan diet. An example of this is the second Denmark study, projected from a Norwegian OECD diet, which has a non-meat diet well below any estimates for a vegan diet. Therefore, Table 3 can display gross errors in assumptions.

Gross errors arise due to a mis-estimation of the portions of meat consumption between the original study and revised OECD numbers. The higher error in the (Saez-Almendros et al. 2013) numbers may arise because beef is estimated larger in the study numbers than OECD-reported. Scarborough et al. (2014) UK study likely has a higher average CO2e meat consumption than the Berners-Lee et al. (2012) UK study. The lower error in the Danish study may arise because Denmark likely eats more EU-like (with pork and chicken) than Norway (beef and not-included sea food).

We also consider why the meat-eater's non-meat GHG/kcal value may be higher than the vegetarian. An explanation may be that it is due to the addition of fish, or because of higher rates of consumption of high-GHG beef, lamb, and cheese. In Table 3, Scarborough et al. (2014) UK study likely considers a higher than average CO2e meat consumption in contrast to the Mediterranean EU diet, with a likely lower than average EU meat consumption.

There is a question of appropriate distribution for the various meats, since fish is not included in the OECD data. Coastal EU nations likely have a high rate of fish consumption, and potentially lower rates of other meats. This model does forgive some error, since Scarborough et al.'s (2014) UK study rates the GHG of chicken and seafood similarly, at $5.4 \mathrm{~kg} \mathrm{CO} 2 \mathrm{e} / \mathrm{kg}$, with pig only slightly higher at 7.9. Therefore, quantities of poultry and fish can be swapped. Pig can be swapped with only slightly higher error.
Table 3: Comparing GHG/kcal for various studies

\begin{tabular}{lllll}
\hline & $\begin{array}{l}\text { Meat } \\
\text { portion }\end{array}$ & $\begin{array}{l}\text { Non- } \\
\text { meat } \\
\text { portion }\end{array}$ & Vegetarian & Vegan \\
\hline Study & ghg/cal & ghg/cal & ghg/cal & ghg/cal \\
\hline $\begin{array}{l}\text { DK (Saxe et al. } \\
\text { 2013) (EU) }\end{array}$ & 5.28 & 1.33 & & \\
$\begin{array}{l}\text { DK (Saxe et al. } \\
\text { 2013) (NW) }\end{array}$ & 6.82 & 0.94 & & \\
$\begin{array}{l}\text { Germany (Meier } \\
\text { \& Christen 2013) } \\
\text { (EU) }\end{array}$ & 5.28 & 2.46 & 2.14 & 1.32 \\
$\begin{array}{l}\text { NL (van de Kamp } \\
\text { et al. 2018) }\end{array}$ & 5.28 & 1.87 & & \\
$\begin{array}{l}\text { NL (van Dooren } \\
\text { et al. 2014) }\end{array}$ & & & 1.60 & 1.33 \\
$\begin{array}{l}\text { Sweden (Röös et } \\
\text { al. 2015) (NW) }\end{array}$ & 6.82 & 1.56 & & \\
$\begin{array}{l}\text { Sweden (Röös et } \\
\text { al. 2015) (EU) }\end{array}$ & 5.28 & 1.78 & & \\
$\begin{array}{l}\text { UK (Scarborough } \\
\text { et al. 2014) (EU) }\end{array}$ & 5.28 & 3.34 & 1.91 & 1.45 \\
$\begin{array}{l}\text { UK (Berners-Lee } \\
\text { et al., 2012) (EU) }\end{array}$ & 5.28 & 1.88 & & \\
$\begin{array}{l}\text { USA (Rose et al. } \\
\text { 2019) }\end{array}$ & 6.61 & 3.79 & & \\
$\begin{array}{l}\text { USA (Saez- } \\
\text { Almendros et al. } \\
\text { 2013) }\end{array}$ & 6.61 & 6.80 & & \\
$\begin{array}{l}\text { USA SDA (Soret et } \\
\text { al. 2014) }\end{array}$ & 6.61 & 1.09 & 1.08 & \\
$\begin{array}{l}\text { US (Heller and } \\
\text { Keoleian 2014) }\end{array}$ & & & & \\
\hline
\end{tabular}

\subsection{Comparison of Diets}

Of the studies we investigated, half of them assumed a kcal of 2000 while the other half estimated above our $2400 \mathrm{kcal}$ ranging between 2412 and 3548 . Therefore, our estimate of $2400 \mathrm{kcal}$ (likely more reasonable than $2000 \mathrm{kcal}$ ) appears low. Two studies assumed higher meat consumption than OECD estimates: Denmark's (Saxe et al. 2013) and USA's (Saez-Almendros et al. 2013) study. The remainder estimated meat consumption low relative to OECD. Since Mediterranean nations were not evaluated, some of these studies should rank above the EU average meat consumption.

Our results show that the GHG is affected both by meat and kcal consumption. Denmark's (Saxe et al. 2013) study is the only study that estimated both higher meat and kcal consumption than this study, and in this one case, our CO2e calculations are lower than theirs.

For the remainder seven studies we estimate higher CO2e results when kcal is matched. One study, USA (Saez-Almendros et al. 2013) assumed a higher meat consumption, but lower kcal. We lowered the meat consumption and raised kcal, and our calculated GHG are higher. Five studies assumed lower meat consumption, and when kcal was matched or raised, GHG estimates rose.

Figure 1 shows a slightly different story, because in this case we matched all studies to a maximum 2400 
kcal. Here two studies' CO2e results dropped, including Denmark and UK (Berners-Lee et al., 2012), basically because both studies estimated kcal at 2726 or higher. Of the remaining studies, CO2e results rose slightly to considerably, even when kcal fell. The average CO2e estimate is $2619 \mathrm{~kg} / \mathrm{year}$, but the range varies wildly between 1817 and 3246 for the EU, and 2300 and 5912 for the US. Since we hoped for a consolidation of results, we plan to further investigate these differences.

Contrasting vegetarian and vegan diets, it is possible to simply use the GHG/kcal statistic to linearly project to $2400 \mathrm{kcal}$. Vegetarian diets average $1360 \mathrm{~kg}$ CO2e/year, ranging between 946 and $1870 \mathrm{~kg} /$ year. Vegan diets average $998 \mathrm{~kg}$ CO2e/year, ranging between 745 and $1266 \mathrm{~kg} /$ year. Thus, meat consumption at $2400 \mathrm{kcal}$ results in about 2.5 tons, whereas vegetarian ranks at $11 / 3$ ton and vegan at slightly less than 1 ton.

\section{Conclusion}

This research leverages previous studies by using an innovative modeling approach to model GHG emissions of dietary consumption. We show it is possible to change components of the diet and recalculate GHG effects, and to investigate whether proposed changes are reasonable by evaluating the GHG/kcal for the non-affected portion of the diet. This is important, because it is helpful to understand the variances in results between studies, but also because the model enables the calculation of theoretical or actual variances in dietary choices.

Many studies rely on dietary estimates, which can underreport consumption. This new model offers another way of calculating consumption, via OECD statistics. While OECD estimates may overestimate meat consumption, it may be the most accurate data available related to retail meat allocation per capita, which is a strong driver of GHG. However, it can be argued that even these greater estimates may be low because data on fish consumption is not readily available. This modeling also helps in investigating differences between studies.

Our results found that both kcal estimates and meat consumption are strong drivers of GHG levels, and research should not be complacent with lower food estimates.

\section{References}

Baroni, L., Cenci, L., Tettamanti, M. and Berati, M. (2007). Evaluating the environmental impact of various dietary patterns combined with different food production systems. European Journal of Clinical Nutrition, 61, 279-286. Nature Publishing Group.

Berners-Lee, M., Hoolohan, C., Cammack, H. and Hewitt, C. N. (2012). The relative greenhouse gas impacts of realistic dietary choices. Energy Policy,
43, 184-190. Elsevier.

Biesbroek, S., Bueno-de-Mesquita, H.B., P. Peeters, P. HM., Verschuren, WM. M., van der Schouw, Y. T., Kramer, G. FH., Tyszler, M. and Temme, E. HM. (2014). Reducing our environmental footprint and improving our health: greenhouse gas emission and land use of usual diet and mortality in EPIC-NL: a prospective cohort study. BioMed Central, April 7 2014. www.ehjournal.net/content/13/1/27.

Eshel, G and Martin, P. A. (2006). Diet, Energy, and Global Warming. Earth Interactions, 10(9), 1-17.

Ganglbauer, E., Fitzpatrick, G. and Molzer, G. (2012). Creating Visibility: Understanding the Design Space for Food Waste. MUM '12: Proc. 11th International Conf. on Mobile and Ubiquitous Multimedia. ACM.

Ganglbauer, E., Fitzpatric, G. and Comber, R. (2013). Negotiating Food Waste: Using a Practice Lens to Inform Design. Transactions on Computer-Human Interaction, 20(2). May 2013, ACM.

Gerber, P.J., Steinfeld, H. Henderson, B., Mottet, A., Opio, C., Dijkman, J., Falcucci, A. and Tempio, G. (2013). Tackling Climate Change through Livestock. Food and Agriculture Organization of the United Nations (FAO).

González-García, S., Esteve-Lorens, X., Moreira, M. T. and Feijoo, G. (2018). Carbon footprint and nutritional quality of different human dietary choices. Science of the Total Environment, 644, 7794. Elsevier.

Greger, M. (2019). How Not to Diet. NutritionFacts.org. ISBN 978-1-250-19922-5.

Heller, Martin C. and Gregory A Keoleian. (2014). Greenhouse Gas Emission Estimates of U.S. Dietary Choices and Food Loss. Journal of Industrial Ecology, 19(3):391-401.

Meier, T.and Christen, O. (2013). Environmental impacts of dietary recommendations and dietary styles: Fermany as an example. Environ. Sci. Technol. https://doi.org/10.1021/3s302152v.

47:877-888.

OECD. (2019). Meat consumption (indicator). doi: 10.1787/fa29ofdo-en (Accessed on 12 July 2019) from https://data.oecd.org/agroutput/meatconsumption.htm, taken 8 January 2020.

Pathak, H., Jain, N., Bhatia, A., Patel, J. and Aggarwal P. K. (2010). Carbon footprints of Indian food items. Agriculture, Ecosystems and Environment, 139, 66-73. Elsevier.

Röös, E., Karlsson, H., Witthöft, C., Sundberg, C. (2015). Evaluating the sustainability of diets-combining environmental and nutritional aspects. Environ. Sci. Pol. https://doi.org/10.1016/j.envsci.2014.12.001.

Saez-Almendros, S., Obrador, B., Bach-Faig, A., SerraMajem, I. (2013). Environmental Footprints of 
Mediterranean versus Western dietary patterns: beyond the health benefits of the Mediterranean diet. Environ. Health, 12, 118-126. https://doi.org/10.1186/1476-069X-12-118.

Saxe, H., Larsen, T.M., Mogensen, L. 2013. The global warming potential of two healty Nordic diets compared with the average Danish diet. Clim Chang. 116:249-262.

Scarborough, P., Appleby, P. N., Mizdrak, A., Briggs A. D. M, Travis, R. C., Bradbury, K. E. and Key, T. J. (2014). Dietary greenhouse gas emissions of meateaters, fish-eaters, vegetarians and vegans in the UK. Climate Change, 125, 179-192, Springer. DOI 10.1007/s10584-014-1169-1.

Sjörs, C., Raposo, S. E., Sjölander, A., Bälter, O., Hedenus, F. and Bälter, K. (2016). Diet-related greenhouse gas emissions assessed by a food frequency questionnaire and validated using 7-day weighed food records. Environmental Health, 15(15).

Soret, S., A. Mejia, M. Batech, K. Jaceldo-Siegl, H. Harwatt, and J. Sabaté. 2014 "Climate change mitigation and health effects of varied dietary patterns in real-life settings throughout North America". American Journal Clinical Nutrition, pp. 490S-5S. American Society for Nutrition.

USA Shrink that Footprint. (n.d.) 7: Shrink your food footprint. Taken from http://shrinkthatfootprint. com/shrink-your-food-footprint, 14 January 2020.

Van de Kamp, M.E., van Dooren, C., Hollander, A., Geurts, M., Brink, E.J. van Rossum, C. Biesbroek, S., de Valk, E. Toxopeus, I.B., Temme, E.H.M. 2018. Healthy diets with reduced environmental impact? - the greenhouse gas emissions of various diets adhering to the Dutch food based dietary guidelines. Food Res. Int. 104:14-24. https://doi.org/10.1016/j.foodres.2017.06.006

Van Dooren, C., Marinusssen, M. Blonk, H., Aiking, H. Vellinga, P. 2014. Exploring dietary guidelines based on ecological and nutritional values: a comparison of six dietary patterns. Food Policy 44:36-46. https://doi.org/10.1016/j.foodpol.2013.11.002. 